\title{
Penanganan Penyelundupan Manusia di Wilayah Pesisir Provinsi Lampung
}

\author{
Dwi Wahyu Handayani ${ }^{1}$, I Gede Sidemen ${ }^{2}$,Yuni Ratnasari ${ }^{3}$ \\ ${ }^{I}$ Department of Government Science, Faculty of Social and Political Sciences,University of Lampung \\ ${ }^{2}$ Department of Sociology, Faculty of Social and Political Sciences, University of Lampung \\ ${ }^{3}$ Department of Sociology, Faculty of Social and Political Sciences,University of Lampung
}

\begin{tabular}{l}
\hline ARTICLE INFORMATION \\
\hline \\
\hline SUBMISSION TRACK \\
\hline Recieved : 30, April 2019 \\
Final Revision : 10, May 2019 \\
Available Online: 30, May 2019 \\
\hline KEYWORD \\
\hline People Smuggling, Vulnerability, Intention, \\
State Capabilities, Local Government
\end{tabular}

KATA KUNCI

Penyelundupan Manusia, Kerentanan, Tujuan, Kapabilitas Negara, Pemerintah Daerah

\section{CORRESPONDENCE}

E-mail: dwi.wahyu@ fisip.unila.id.

\begin{abstract}
Lampung Coastal Area is an area that is visited by immigrants who seek asylum and refugees before heading to the destination country, because of conflict and they want to get a better life from their home countries. While maritime development must pay attention to social security. The purpose of this study is to get a development model for cooperation in handling human smuggling issue in Lampung Coastal Area. The researcher used the Lani Kass formula regarding non traditional security threats. The researcher explained with qualitative descriptive methods about three aspects, such as the vulnerability of the country, the purpose of the entry of foreigners, and the capability of the state. The results of this study show there are local government security vulnerabilities due to illegal migrants and human smuggling issues. However, the handling of human smuggling issue in the regions highly depends on the policies, budgets, central government programs, and international cooperation networks
\end{abstract}

\section{ABSTRAK}

Pesisir Lampung adalah wilayah yang disinggahi para imigran pencari suaka dan pengungsi sebelum menuju negara tujuan, karena konflik dan ingin mendapat kehidupan lebih baik dari negara asal. Sementara pembangunan maritim harus memperhatikan keamanan sosial. Tujuan penelitian ini adalah mendapatkan pengembangan model kerjasama penanganan penyelundupan manusia di Wilayah Pesisir Lampung. Peneliti menggunakan formula Lani Kass mengenai ancaman keamanan non tradisional. Peneliti menjelaskan dengan metode kualitatif deskriptif mengenai tiga aspek yaitu kerentanan negara, tujuan masuknya orang asing dan kapabilitas negara. Hasil penelitian ini bahwa ada kerentanan keamanan pemerintah daerah akibat migran illegal dan penyelundupan manusia. Namun penanganan penyelundupan manusia di daerah sangat tergantung pada kebijakan, anggaran, program pemerintah pusat, hingga jaringan kerjasama internasionalnya. 


\section{Provinsi Lampung}

\section{Pendahuluan}

Kebijakan pembangunan tidak lepas dari aspek keamanan sosial, salah satunya adalah arus migran ilegal yang datang dari negara lain dengan tujuan memeroleh perlindungan. Kecenderungan peningkatan arus migran ilegal diiringi dengan tuntutan dunia internasional bahwa pemerintah harus tetap memberikan perlindungan atas dasar kemanusiaan. Kantor Imigrasi Kelas I Bandar Lampung mencatat sejak tahun 2012 hingga 2015 telah menahan 108 imigrangelap di Ruang Detensi
Imigrasi.Kepala Kantor Imigrasi Kelas I Bandar Lampung menjelaskan sejak 2012 hingga akhir 2014 sebanyak 99 orang imigran ilegal, pencari suaka, dan pengungsi pernah mendekam di Ruang Detensi. Mereka berkebangsaan Afganistan (20 orang), Bangladesh (20), Myanmar (35 orang), Pakistan (6 orang), Sudan (7 orang), dan Somalia (11 orang). November 2013 sebanyak 50 imigran gelap asal negara Myanmar, Bangladesh, Pakistan, Nepal, Sudan diamankan di Bakauheni. Pada tabel 1 menunjukkan distribusi keberadaan imigran ilegal di Indonesia.

Tabel 1. Distribusi Imigran Illegal di Indonesia

\begin{tabular}{clccccc}
\hline \multirow{2}{*}{ No. Regional Police Headquarters } & \multicolumn{3}{c}{ Year } \\
\cline { 3 - 7 } & & $\mathbf{2 0 0 8}$ & $\mathbf{2 0 0 9}$ & $\mathbf{2 0 1 0}$ & $\mathbf{2 0 1 1}$ & $\mathbf{2 0 1 2}$ \\
\hline 1. & West Java & - & 25 & 239 & 82 & 790 \\
\hline 2. & Banten & 20 & 289 & 217 & 101 & 762 \\
\hline 3. & East Java & - & 112 & 347 & 213 & 469 \\
\hline 4. & West Nusa Tenggara & 79 & 195 & 192 & 41 & 359 \\
\hline 5. & Criminal Investigation Bureau & - & - & - & - & 320 \\
\hline 6. & East Nusa Tenggara & 12 & 213 & 604 & 258 & 221 \\
\hline 7. & Metro Jaya & - & - & 1 & 21 & 195 \\
\hline 8. & Lampung & - & 22 & 293 & 122 & 185 \\
\hline 21. & Papua & 6 & - & - & - & - \\
\hline & Total & 116 & 996 & 2.352 & 2.470 & 3.801 \\
\hline
\end{tabular}

Sumber: Case Management Intelligent System (CMIS) PS the Unit of Criminal Investigation Bureau, Indonesia Police Headquarters. Penanganan Penyelundupan Manusia di Indonesia. The Handling of People Smuggling in Indonesia. 2012 ( Rizkan Zulya, Geetha Subramaniam, Tan Kamello: 2014).

Berdasarkan data Badan Reserse Kriminal Polri Direktorat Tindak Pidana Umum Sub Direktorat III Unit People Smuggling bahwa Riau, Kepulauan Riau, Kalimatan Barat, Kalimantan Timur, Banten, Jawa Timur, Bali dan Sulawesi Selatan sebagai lokasi masuknya para imigran gelap ke Indonesia. Sedangkan Lampung sebagai salah satu lokasi keluar atau pemberangkatan para imigran gelap menuju Australia, lainnya adalah Sumatera Utara, Riau, Kepulauan Riau, Sumatera Barat, Banten, Jawa Barat, Jawa Timur, Sulawesi Selatan, Sulawesi Tenggara, Madura, Nusa Tenggara Barat dan
Nusa Tenggara Timur. ${ }^{1}$ Oleh sebab itu, perlu ada penelitian mengenai bagaimana penanganan penyelundupan manusia di Provinsi Lampung, Lampung memiliki perairan yang terbuka dari arah barat dan juga merupakan lintas yang paling mudah dilalui dari satu pulau ke pulau lainnya. Tujuan khusus adalah peneliti mendapatkan

\footnotetext{
1 Netanyahu, Kurniawan. 2018. Upaya Penanganan People Smuggling Oleh Sekretariat NCB-INTERPOL Indonesia Dan Australian Federal Police Tahun 2015 - 2017. Skripsi, Program Studi Hubungan Internasional Fakultas Ilmu Sosial dan Ilmu Komunikasi, Universitas Satyawacana.
} 


\section{Manusia di Wilayah Pesisir \\ Provinsi Lampung}

pengembangan model kerjasama penanganan penyelundupan manusia di Wilayah Provinsi Lampung.

\section{Metode Penelitian}

Penelitian ini menggunakan metode kualitatif dengan pendekatan deskriptif. Tujuannya agar dapat mendeskripsikan beberapa hal terkait analisa ancaman, modus operandi dan jaringan, serta tantangan kebijakan dari berbagai stakeholder. Selanjutnya dari semua data-data yang telah dipilah peruntukannya bagi masing-masing analisa akan disusun kembali, sehingga menghasilkan model penanganan penyelundupan manusia melalui wilayah Provinsi Lampung.

Barry Buzan menjelaskan konsep keamanan berada di dua interaksi perdebatan. Argumen pertama diusung oleh pemikiran tradisionalis yang mengatakan bahwa ancaman keamanan negara diindikasikan dengan adanya kompetisi dan masalah keamanan antar negara, misal adanya perlombaan senjata (arm race) dan pembangunan kekuatan militer (military build-up) sehingga berdampak pada ancaman keamanan nasionalnya. Kelompok nontradisionalis mengatakan bahwa masalah keamanan suatu negara harus memasukkan masalah keamanan intra-negara dan masalah keamanan transnasional. Masalah keamanan intra-negara adalah misalnya terjadinya kekacauan (disorder) di dalam negara oleh masyarakat atau penduduk karena etnik, ras (warna kulit), agama, linguistik atau strata ekonomi. Sedangkan masalah keamanan transnasional misalnya munculnya ancaman yang disebabkan oleh arus migrasi, kerusakan lingkungan hidup dan masalah kependudukan seperti besarnya jumlah penduduk (over population).

Buzan memahami keamanan sebagai persoalan yang berkaitan dengan nasib manusia sebagai kolektivitas. Keamanan menurutnya mencakup ancaman yang berasal dari luar maupun ancaman yang berasal dari dalam (negeri) sendiri. Bagi negara yang memiliki banyak akses lintas negara semakin memperbesar peluang terhadap terjadinya tindakan kejahatan transnasional. Semakin meningkatnya keberadaan orang asing secara ilegal di suatu negara memberikan kerugian bagi negara tersebut, baik secara finansial dan material.

Sejalan dengan ide Buzan tentang ancaman keamanan non-tradisional, Lani Kass, seorang doktor di bidang ahli strategis dari National War College AS juga pernah menulis dalam artikel ilmiahnya yang berjudul "Strategic Review" yang membagi ancaman ke dalam tiga bagian yaitu ancaman internal, ancaman eksternal dan ancaman intraeksternal. Ancaman internal adalah ancaman yang berasal dari dalam negara, seperti adanya terorisme dan konflik komunal yang dapat menghasilkan ancaman keamanan non-tradisional. Ancaman eksternal adalah ancaman yang berasal dari luar negara, yang seringkali diidentikan dengan ancaman dari negara lain atau negara musuh. Sementara ancaman internaleksternal merupakan ancaman yang tidak dapat dipastikan secara tepat sumbernya, seperti serangan terorisme global.

Pada ancaman keamanan nontradisional, khususnya masalah keamanan transnasional dari aktifitas migrasi ilegal, dikategorikan dengan formula berikut:

\section{Gambar 1. Formula Terjadinya Ancaman Dari Lani Kass ${ }^{2}$}

Vulnerabilities $x$ Intention $x$ Capabilities $=$ Threat

Dari formula di atas dapat dijelaskan bahwa terdapat tiga aspek yaitu kerentanan negara (vulnerabilities), tujuan masuknya orang asing (intention) dan kapabilitas negara (capabilities). Jika ketiga aspek

\footnotetext{
${ }^{2}$ Kass, Lani. Homeland Defense: Assumption First, Strategy Second. Journal of Homeland Security. Vol. 1, 2004: 187-200.
} 


\section{Manusia di Wilayah Pesisir \\ Provinsi Lampung}

tersebut dikolaborasikan menjadi berpengaruh terhadap tingkat ancaman. Perubahan tingkat pada satu aspek yang terdapat di dalam formula tersebut dapat langsung berpengaruh pada tingkat ancaman. Misal suatu negara memiliki tingkat kerentanan yang tinggi dalam isu kedaulatan atau isu konflik suku, ras dan antar golongan (SARA), ditambah dengan banyaknya orang asing yang memasuki negara tersebut namun ia memiliki kapabilitas yang baik dalam hal kemapanan ekonomi dan militer sebagai penangkal atas kerentanan dan masuknya orang asing, maka terjadi penurunan pada tingkat ancaman. Kass mengatakan tentang pengukuran penurunan kerentanan dengan meningkatkan perlindungan tanah air dengan aspek-aspek seperti kesiapan, kesiagaan dan prioritas.

Kejahatan transnasional terkait migrasi adalah penyelundupan manusia (people smuggling). Pasal 3 Protokol PBB Tahun 2000 tentang kejahatan transnasional terorganisasi memberikan definisi smuggling of migrants sebagai sebuah usaha pengadaan secara sengaja untuk sebuah keuntungan bagi masuknya seseorang secara ilegal ke dalam suatu negara dan/atau tempat tinggal yang ilegal dalam suatu negara, dimana orang tersebut bukan merupakan warga negara atau penduduk tetap dari negara yang dimasuki.

Penyelundupan

(smuggling)

merupakan suatu istilah yang biasanya diperuntukkan bagi individu atau kelompok, demi keuntungan, memindahkan orangorang secara tidak resmi (melanggar ketentuan undang-undang) untuk melewati perbatasan suatu negara. Penyelundupan orang (people smuggling) dapat terjadi dengan persetujuan dari orang atau kelompok yang berkeinginan untuk diselundupkan dengan berbagai alasan yang melatarbelakanginya. Sedangkan Imigran gelap (illegal migration) diartikan sebagai salah satu usaha untuk memasuki suatu wilayah tanpa izin. Imigran gelap diartikan pula seseorang atau sekelompok orang yang menetap di suatu wilayah melebihi batas waktu berlakunya izin tinggal yang sah atau tidak memenuhi persyaratan untuk masuk ke suatu wilayah secara sah. Illegal migration diartikan sebagai suatu usaha untuk memasuki suatu wilayah tanpa izin. Imigran gelap dapat pula berarti bahwa menetap di suatu wilayah melebihi batas waktu berlakunya izin tinggal yang sah atau melanggar atau tidak memenuhi persyaratan untuk masuk ke suatu wilayah secara sah. Terdapat tiga bentuk dasar dari imigran gelap. Yang pertama adalah yang melintasi perbatasan secara ilegal (tidak resmi). Yang kedua adalah yang melintasi perbatasan dengan cara, yang secara sepintas adalah resmi (dengan cara yang resmi), tetapi sesungguhnya menggunakan dokumen yang dipalsukan atau menggunakan dokumen resmi milik seseorang yang bukan haknya, atau dengan menggunakan dokumen remsi dengan tujuan yang ilegal. Dan yang ketiga adalah yang tetap tinggal setelah habis masa berlakunya status resmi sebagai imigran resmi.

\section{Hasil Pembahasan}

\section{Analisa Ancaman Kerentanan Negara}

Secara geografis, letak Indonesia yang berada di antara dua samudera dan dua benua yang menjadikan Indonesia sebagai penghubung antara benua Asia dan benua Australia. Hal tersebut pula yang mendasari Indonesia sebagai negara transit utama oleh para imigran untuk menuju ke Australia sebagai negara tujuan mereka. Sehingga hal tersebut pula yang mendasari Indonesia sebagai negara transit utama oleh para imigran untuk menuju ke Australia sebagai negara tujuan mereka. Selain itu, Indonesia yang merupakan negara kepulauan tentu memiliki banyak celah yang dapat dimanfaatkan oleh para imigran gelap yang tidak serta merta mempunyai tujuan yang sama, ada yang menjadikan Indonesia sebagai negara transit sebelum menuju ke Australia, namun banyak pula yang memang ingin tinggal guna mendapatkan 


\section{Manusia di Wilayah Pesisir \\ Provinsi Lampung}

penghidupan yang lebih layak daripada di negara asalnya.

Selain itu, ketidaktahuan masyarakat setempat akan kejahatan penyelundupan manusia serta kebutuhan ekonomi juga menjadi faktor penyebab peningkatan kasus penyelundupan manusia. Masyarakat setempat terlibat dalam penampungan sementara dan menyeberangkan para imigran tersebut dengan diberi imbalan. Alasan yang kerap kali diberikan oleh para imigran yang diselundupkan adalah untuk mendapatkan pekerjaan atau memperbaiki status ekonomi, harapan untuk mendapatkan penghidupan yang lebih baik, dan rasa aman dari konflik di negaranya.

Pelaku penyelundupan manusia dapat berasal dari warganegara asing dan warganegara Indonesia. Baik warganegara asing dan warganegara Indonesia dapat masuk dalam kategori otak pelaku penyelundupan maupun memiliki keterlibatan. Keterlibatan warganegara Indonesia sebagai otak pelaku dapat dengan merekrut korban dari negara setempat yang sama kewarganegaraannya, dengan alasan mendapatkan kehidupan yang lebih layak. Keterlibatan warganegara Indonesia sebagai bagian dari pelaku penyelundupan dapat berperan pada negara transit, untuk tujuan penampungan sementara, menguruskan dokumen palsu keimigrasian berupa paspor dan visa menuju negara penempatan. Kemudian memberikan penyewaan fasilitas pemberangkatan seperti perahu (apabila tanpa dokumen) dan kendaraannya.

Bersamaan dengan masuknya irregular migration akan diikuti dengan masuknya isu lainnya seperti penyakit menular, penyelundupan barang, narkotika dan manusia, bahkan terkait dengan kelompok teroris. Secara historis, sebagai negara transit, Indonesia telah mengakomodasi keberadaan pengungsi untuk sementara berada dalam wilayah yurisdiksi Indonesia. Masuknya irregular migrant ke Indonesia bersamaan juga dengan adanya ancaman terhadap keamanan negara.
Pencari suaka yang singgah di Indonesia rawan menjadi kurir kejahatan transnasional seperti kejahatan perdagangan narkotika dan terorisme.

\section{Tujuan Masuk (Intention)}

Lokasi rentan penyelundupan manusia di Provinsi Lampung adalah di Pelabuhan Bakauheni, Pelabuhan Panjang (yang merupakan terminal peti kemas), area Lempasing, Pantai Labuhan Maringgai, Ujung Bom, Pulau Sebesi, Legundi, Rimau Balak, dan juga desa-desa yang terletak di jalur garis pantai. Pelabuhan Panjang bisa menjadi target penyelundupan manusia karena sangat sulit untuk memantau siapa di kapal. Migran nonreguler bisa datang melalui jalur darat, misal darat dari Medan, Riau atau melalui jalur laut dengan kapal di Selat Sunda.

Dalam konteks Indonesia, yang menjadi faktor penarik untuk terjadinya praktik kejahatan ini antara lain adalah keadaan geografis Indonesia yang luas, tetapi kekurangan satuan tugas pengamanan wilayah. Indonesia adalah negara yang strategis sebagai tempat transit sebelum sampai ke negara tujuan, seperti Australia.

Migrasi ilegal yang terjadi di Indonesia khususnya di pulau-pulau perbatasan Indonesia berimplikasi pada munculnya masalah keamanan berupa aksiaksi (transnational crime), juga kejahatan transnasional yang terorganisir (transnational organized crime).

Seperti yang terjadi di daerah lain, visibilitas rute penyelundupan di Asia Tenggara tidak merata - beberapa rute sangat terlihat, sementara yang lain tetap ada sebagian besar tidak diketahui. Rute yang paling terlihat cenderung menjadi penyelundupan rute maritim di wilayah ini, terutama yang berasal dari Bangladesh dan Myanmar melintasi Teluk Benggala dan Laut Andaman ke Thailand, Malaysia dan Indonesia, dan juga dari Indonesia (dan Sri Lanka) ke Australia - keduanya terutama terdiri dari pencari suaka. Rute 
Dwi Wahyu H, I Gede Sidemen, Yuni Ratnasari | Penanganan Penyelundupan

Manusia di Wilayah Pesisir

Provinsi Lampung

penyelundupan lain diketahui didominasi antara Indonesia dan Malaysia, misalnya).

oleh pekerja illegal migran (pada tabel 2 .

Tabel 2. Resiko Populasi Kawasan: Pengungsi, Pencari Suaka, Pengungsi Internal dan Orang Tanpa Kewarganegaraan, 2014

\begin{tabular}{|c|c|c|c|c|c|c|c|c|c|}
\hline & \multicolumn{3}{|c|}{ As a receiving country } & \multicolumn{3}{|c|}{ Internal at risk populations } & \multicolumn{3}{|c|}{ As an origin country } \\
\hline & $\begin{array}{l}\text { Refugees } \\
\text { (1) }\end{array}$ & $\begin{array}{l}\text { Asylum } \\
\text { seekers }\end{array}$ & Total & $\begin{array}{l}\text { Interna } \\
\text { lly } \\
\text { displac } \\
\text { ed }\end{array}$ & Stateless & Total & $\begin{array}{l}\text { Refugees } \\
\text { (1) }\end{array}$ & $\begin{array}{l}\text { Asylu } \\
\mathrm{m} \\
\text { seeker } \\
\mathrm{s} \\
\end{array}$ & Total \\
\hline Australia & 55,598 & 22,745 & $\begin{array}{c}78,34 \\
3 \\
\end{array}$ & - & - & - & 25,000 & 6,000 & $\begin{array}{c}31,00 \\
0\end{array}$ \\
\hline $\begin{array}{l}\text { Brunei } \\
\text { Darussalam }\end{array}$ & - & - & - & - & 20,524 & 20,524 & 1,000 & 1,000 & 2,000 \\
\hline Cambodia & 63,000 & 40,000 & $\begin{array}{c}103,0 \\
00 \\
\end{array}$ & - & - & - & 13,062 & $\begin{array}{c}263,0 \\
00 \\
\end{array}$ & $\begin{array}{c}13,32 \\
5 \\
\end{array}$ \\
\hline Indonesia & 4,270 & 6,916 & $\begin{array}{c}11,18 \\
6\end{array}$ & - & - & - & 14,408 & 1,773 & $\begin{array}{c}16,18 \\
1\end{array}$ \\
\hline $\begin{array}{l}\text { Lao People's } \\
\text { Democraric } \\
\text { Republic }\end{array}$ & - & - & - & - & - & - & 7,482 & $\begin{array}{c}117,0 \\
00\end{array}$ & 7,599 \\
\hline Malaysia (2) & 99,381 & 51,240 & $\begin{array}{c}150,6 \\
21\end{array}$ & & 40,000 & 40,000 & 468,000 & $\begin{array}{c}957,0 \\
00 \\
\end{array}$ & 1,425 \\
\hline Myanmar & - & - & - & $\begin{array}{c}376,50 \\
0 \\
\end{array}$ & 810,000 & $\begin{array}{c}1,186, \\
500\end{array}$ & 479,001 & $\begin{array}{c}51,34 \\
7 \\
\end{array}$ & $\begin{array}{c}530,3 \\
48 \\
\end{array}$ \\
\hline $\begin{array}{l}\text { Philippines } \\
\text { (2) }\end{array}$ & 222,000 & 109,000 & $\begin{array}{c}331,0 \\
00\end{array}$ & $\begin{array}{c}142,43 \\
0\end{array}$ & 6,370 & $\begin{array}{c}148,80 \\
0\end{array}$ & 668,000 & 1,118 & 1,786 \\
\hline Singapore & 3,000 & - & 3,000 & - & - & - & 59,000 & $\begin{array}{c}38,00 \\
0\end{array}$ & $\begin{array}{c}97,00 \\
0 \\
\end{array}$ \\
\hline Thailand & 130,238 & 7,931 & $\begin{array}{c}138,1 \\
69 \\
\end{array}$ & - & 506,197 & $\begin{array}{c}506,19 \\
7 \\
\end{array}$ & 231,000 & $\begin{array}{c}413,0 \\
00\end{array}$ & $\begin{array}{c}644,0 \\
00\end{array}$ \\
\hline Timor Leste & - & - & - & - & - & - & 13,000 & $\begin{array}{c}10,00 \\
0\end{array}$ & $\begin{array}{c}23,00 \\
0\end{array}$ \\
\hline \multirow[t]{2}{*}{ Vietnam } & - & - & - & - & 11,000 & 11,000 & 313,418 & 3,140 & $\begin{array}{c}316,5 \\
58 \\
\end{array}$ \\
\hline & \multicolumn{3}{|c|}{378,756} & \multicolumn{3}{|c|}{$1,913,021$} & \multicolumn{3}{|c|}{888,019} \\
\hline
\end{tabular}

Source: UNHCR, 2015.

Notes: (1) Refugees include persons in refugee-like situations.

(2) Figures do not include 80,000 Filipino Muslims currently in Malaysia without status, and as reported in the "other" category in UNHCR's Global Trends 2014.

Anne Gallagher and Marie McAuliffe. 2016. South-East Asia and Australia dalam Migrant Smuggling Data and Research: A global review of the emerging evidence base, In ternational Organization for Migration hal 225.

Pengungsi Internasional yang terkenal antara lain adalah mengenai boat people (manusia perahu), julukan yang dulu juga diberikan kepada orang-orang Vietnam yang lari dari negaranya menggunakan perahu karena perang. Para pencari suaka menggunakan perahu untuk mencapai negara

tujuan yaitu Australia, dengan melintasi daerah teritorial Indonesia. Tidak sedikit dari "boat people" ini yang tidak mempunyai surat-surat dan dokumen resmi, sehingga termasuk dalam kategori imigran gelap dan dimasukkan ke panti imigrasi adapula yang berkeliaran dan hidup membaur dengan 


\section{Manusia di Wilayah Pesisir \\ Provinsi Lampung}

masyarakat (menunggu saat yang tepat untuk berangkat menuju Australia). Ada bahkan yang akhirnya menikah dengan penduduk Indonesia supaya lebih "aman". Bagi yang belum tertangkap ini, sebelum menginjakkan kaki ke Indonesia mereka sudah mengantongi nama-nama sindikat/calo yang siap dihubungi. Sindikat ini (biasanya ada yang aparat militer dan cukong kapal) akan mengatur orang-orang yang akan diberangkatkan menggunakan perahu nelayan seadanya. Sindikat ini akan mengatur dan mengusahakan agar perjalanan perahu ini bisa mencapai Christmas Island yang merupakan salah satu titik terluar Australia yang dekat dengan Indonesia (jaraknya kira-kira $400 \mathrm{~km}$ ) dari pantai selatan Jawa Barat, atau kira-kira berjarak antara Jakarta-Semarang. ${ }^{3}$ Penyelundupan manusia juga menyelundupkan para imigran ilegal ke Ashmore Reef (Australia). Australia menjadi negara tujuan para imigran ilegal karena Australia meratifikasi konvensi pengungsi, sehingga mereka menganggap Australia akan memberikan perlindungan sesuai dengan kewajiban yang diatur oleh konvensi, walaupun para imigran tersebut masuk ke wilayah Australia secara ilegal. ${ }^{4}$

\section{Kapabilitas Pemerintah}

\section{a. Kebijakan dan Jaringan Kerjasama}

Indonesia belum meratifikasi Konvensi 1951 tentang Status Pengungsi dan Protokol 1967, sehingga tidak ada hukum nasional khusus yang mengatur tentang status dan keberadaan para pencari suaka di Indonesia.

\footnotetext{
${ }^{3}$ Septia Anggrainy, Vindy, Perlindungan Pengungsi Lintas Batas Negara di Indonesia Menurut Hukum Internasional, Lex et Societatis, Vol. II, No. 1, Januari 2014.

4 Kristin, Debby dan Chloryne Trie Isana Dewi, Tindak Pidana Kejahatan Penyelundupan Manusia (People Smuggling) di Indonesia: Tanggung Jawab Indonesia dan Australia. Padjadjaran Journal of International Law, Volume 1, Number 1, Januari 2017.
}

Selama ini penanganan atas pencari suaka dan pengungsi di Indonesia dilaksanakan oleh Direktorat Jenderal Imigrasi sebagai lembaga pengawas orang asing. Indonesia menyerahkan kewenangan penentuan status pencari suaka pada UNHCR, dengan dibantu oleh IOM yang selama ini memberikan bantuan materi untuk kebutuhan pangan dan medis para pencari suaka yang tinggal di rudenim. ${ }^{5}$

Namun demikian, Indonesia sebagai negara pihak United Nations Convention Against Transnational Organized Crime (UNTOC) dan Palermo Protocol, Indonesia mempunyai kewajiban dalam rangka pencegahan dan pemberantasan tindak pidana penyelundupan manusia. ${ }^{6}$

Indonesia meratifikasi konvensi tersebut melalui Undang-Undang No. 5 tahun 2009. Seiring perkembangannya pada tahun 2004 dibentuk protokol tambahan dari UNTOC tahun 2000 tersebut yaitu Protokol Menentang Penyelundupan Migran Melalui Darat, Laut, dan Udara melengkapi Konvensi Perserikatan Bangsa-Bangsa Menentang Tindak Pidana Transnasional yang Terorganisir. Protokol tambahan ini sudah diratifikasi oleh Indonesia melalui UndangUndang No. 15 Tahun 2009.

Selanjutnya hak untuk mencari suaka dijamin di dalam UUD RI Tahun 1945, pasal 28G ayat (2) yang berbunyi: "Setiap orang berhak untuk bebas dari penyiksaan atau perlakuan yang merendahkan derajat manusia dan berhak memeroleh suaka politik dari negara lain”. UU No 39 Tahun 1999 tentang HAM juga menjamin bahwa "Setiap orang berhak mencari suaka untuk memeroleh perlindungan politik dari negara lain. Selanjutnya UU No 37 Tahun 1999

\footnotetext{
5 MoU Komnas HAM dan UNHCR Dorong Perlindungan Pengungsi dan Pencari Suaka, https://www.komnasham. go.id/index.php/ news/2015 /07/28/173/mou-komnas-ham-dan-unhcr-dorong-perlindungan-pengungsi-dan-pencari-suaka.html. Selasa, 28 Juli 2015. Akses pada Senin 30 Oktober 2017.

${ }^{6}$ Op. Cit. Debby Kristin dan Chloryne Trie Isana Dewi: 2017.
} 


\section{Manusia di Wilayah Pesisir \\ Provinsi Lampung}

tentang Hubungan Luar Negeri, menyatakan bahwa pengungsi dan pencari suaka secara khusus diatur oleh Keppres (Keputusan Presiden), meski hingga saat ini keppres belum dibuat. Satu-satunya aturan hukum yang digunakan oleh pemerintah Indonesia, khususnya pejabat imigrasi untuk mengatur soal pencari suaka dan pengungsi adalah surat edaran IMI-1489.UM.08.05 yang dikeluarkan oleh Dirjen Imigrasi pada tahun 2010. Surat edaran tersebut mengetahui bahwa setiap imigran yang mencari suaka tidak akan dideportasi, mereka akan dirujuk ke UNHCR.

Dipertegas dengan adanya UU No.15 Tahun 2009 tentang Pengesahan Protokol Menentang Penyelundupan Migran melalui Darat, Laut dan Udara, melengkapi konvensi Perserikatan Bangsa-Bangsa menentang Tindak Pidana Transnasional yang Terorganisasi. Dalam UU No.15 Tahun 2009 tentang ratifikasi protokol menentang penyelundupan, namun belum ada undangundang khusus tentang tindak pidana penyelundupan manusia/imigran di Indonesia. Fenomena masuknya imigran gelap ke Indonesia tersebut sudah memenuhi syarat sebagai people smuggling, namun karena ketiadaan undang-undang khusus, Polri hanya menggunakan Undang-Undang Imigrasi dalam proses penyidikan. Hal ini yang menyebabkan masalah bahwa yang menjadi tersangka kemudian hanyalah warga negara Indonesia, sedangkan para imigran gelap berlindung di bawah konsel people smuggling dan lepas dari tuntutan hukum Indonesia. ${ }^{7}$

Indonesia memiliki kebijakankebijakan dalam penanganan imigran yang telah diatur dalam Undang-Undang Nomor 6 Tahun 2011 tentang Keimigrasian dan Peraturan Pemerintah Republik Indonesia

\footnotetext{
7 Zikri, Manshur, Permasalahan Imigran Gelap Dan People Smuggling Dan Usaha-Usaha Serta Rekomendasi Kebijakan dalam Menanggulanginya. Tugas Akhir Mata Kuliah Kebijakan Kriminal, Fakultas Ilmu Sosial Dan Ilmu Politik, Universitas Indonesia, 2010.
}

Nomor 31 Tahun 2013 Tentang Peraturan Pelaksanaan Undang-Undang Nomor 6 Tahun 2011 Tentang Keimigrasian.

Lalu lintas keluar dan masuk orang dari dan ke dalam Indonesia telah diatur dalam Undang-Undang Imigrasi No 6/2011. Namun permasalahan yang muncul adalah banyak dari imigran yang masuk secara ilegal dan berlindung di balik status pengungsi atau pencari suaka belum dapat dipastikan bisa mendapatkan status tersebut dari UNHCR sehingga hukum di Indonesia terabaikan. Selain itu, imigran gelap yang masuk ke Indonesia dianggap sebagai korban penyelundupan orang, padahal undangundang tentang people smuggling tidak ada di Indonesia, mengakibatkan para imigran gelap merasa sangat aman di Indonesia, merasa bebas tanpa dikenakan hukum Indonesia. Yang terjerat hukum Indonesia hanyalah WNI yang juga ikut terlibat (terhasut oleh para penyelundup) dalam penyelundupan manusia, dan mereka juga terjerat oleh hukum Australia. ${ }^{8}$

Selanjutnya permasalahan arus pengungsi lintas batas di Indonesia memerlukan kerjasama antara lembaga pemerintah Indonesia serta perangkatnya. Atas prakarsa kerjasama IOM, Dirjen Imigrasi dan Mabes Polri dibentuklah suatu mekanisme antar lembaga penegak hukum (Imigrasi, The Indonesian National Police (INP), TNI, pemerintah daerah setempat) dengan masyarakat untuk mengidentifikasi para imigran illegal di daerahnya masingmasing. Juga melibatkan Komnas HAM dalam rangka meningkatkan advokasi dan perlindungan terhadap hak asasi manusia para pengungsi. Penanganan penyelundupan manusia di Indonesia dikoordinasikan melalui jaringan lembaga Badan Koordinasi Utama adalah Kementerian Koordinasi Politik, Hukum, dan Keamanan. Melalui Desk Penyelundupan Manusia-badan nasional antardepartemen untuk Pengungsi, Pencari Suaka, dan Penyelundupan Manusia

\footnotetext{
${ }^{8}$ Ibid.
} 


\section{Manusia di Wilayah Pesisir \\ Provinsi Lampung}

terjalin kerjasama dengan Kepolisian RI, Kementerian Luar Negeri dan Imigrasi. ${ }^{9}$

Penanganan penyelundupan manusia di Lampung yang dilakukan oleh pihak kepolisian daerah dengan membentuk Satgasda People Smuggling, merupakan kelanjutan dari terbentuknya Satgas People Smuggling di pusat yaitu Bareskrim Polri atau dikenal sebagai Satgaspus People Smuggling tahun 2009.

Dalam penelitian Kurniawan Netanyahu, menjelaskan bahwa Satgas People Smuggling memiliki masa jabatan selama satu tahun dan dapat diperpanjang dengan berdasarkan keputusan Pimpinan Polri. Satgas People Smuggling pada bulan Juni 2015 tidak diperpanjang dan penanganan kasus People Smuggling berada di tangan Unit III Sub Direktorat III Tindak Pidana Umum. Dukungan anggaran diperoleh dari DIPA Polri.

Bila sebelumnya pihak AFP (Australian Federal Police) memberikan hibah berupa sarana dan prasarana kini dialihkan kepada Satgas TPPO (Tindak Pidana Perdagangan Orang). Selanjutnya terdapat juga Sekretariat National Central Bureau (NCB) Interpol Indonesia yang menginduk pada International Criminal Police (ICPO)-Interpol yang berpusat di Lyon Perancis. Terbentuk dari adanya persamaan kepentingan dalam memberantas kejahatan transnasional dan internasional yang terjadi di negara-negara di dunia. NCB Interpol memiliki peranan yang sangat penting yaitu terkait dengan pembuatan MoU (Memorandum of Understanding) dan agreement dengan pihak-pihak yang memiliki permasalahan yang sama terkait tindak kejahatan People Smuggling. ${ }^{10}$

\footnotetext{
${ }^{9}$ Upaya Memerangi Penyelundupan Manusia Pada Tahun 2013. 2014. Report IOM Indonesia Januari 2014: 3 .

${ }^{10}$ Netanyahu, Kurniawan. 2018. Upaya Penanganan People Smuggling Oleh Sekretariat NCBINTERPOL Indonesia Dan Australian Federal Police Tahun 2015 - 2017, Skripsi, Program Studi Hubungan Internasional Fakultas Ilmu Sosial dan Ilmu Komunikasi, Universitas Satyawacana.
}

Penanganan migran ilegal di Provinsi Lampung menurut pihak Kantor Imigrasi Kelas 1 Bandar Lampung menggunakan UU Keimigrasian, ada tim khusus yang melibatkan antarlembaga, Imigrasi, Polda, Dinas Sosial, Dinas Pendidikan, Dinas Kependudukan, unsur masyarakat, IOM dan UNHCR. Sejak perubahan kebijakan Australia yang menutup pintu bagi pengungsi tahun 2014, Polda Lampung mengaku tidak ada kerjasama antara Polda dan Kepolisian Australia, dan kegiatan khusus pengamanan indikasi people smuggling. Pihak Imigrasi juga mengaku penanganan people smuggling menjadi masuk ke tim pengawasan orang asing.

Lampung dalam penanganan penyelundupan manusia telah melaksanakan Public Information Campaign (PIC) sejak tahun 2008. Permasalahan dalam penanganan adalah sebagian besar aparatur terkait di level pemerintah daerah kabupaten belum memahami persoalan migran ilegal. Demikian juga dengan staf administrasi pelabuhan hanya memiliki sedikit pemahaman tentang masalah penyelundupan manusia. $^{11}$ Dari sisi penjagaan keamanan, menurut Polda Lampung dalam wawancara Oktober tahun 2017, tidak ada pintu keluar masuk khusus orang asing di pelabuhan laut khususnya di Bakauheni Lampung.

Polda Lampung pada tahun 2012 meresmikan gedung penampungan korban penyelundupan manusia. Pendirian gedung tersebut dilatarbelakangi Provinsi Lampung sebagai salah satu provinsi dengan tingkat penyelundupan imigran gelap terbanyak di Pulau Sumatera. Penyelundupan imigran gelap tersebut karena faktor Lampung memiliki perairan yang terbuka dari arah barat dan juga merupakan lintas yang paling mudah dilalui dari satu pulau ke pulau lainnya. Dengan diresmikannya gedung

\footnotetext{
${ }^{11}$ IOM Indonesia Irregular Migrant People Smuggling Public Information Campaign (PIC). Market Research Report Klirkom. Released Under The FOI Act 1982: 32-38).
} 


\section{Manusia di Wilayah Pesisir \\ Provinsi Lampung}

penampungan imigran gelap, diharapkan tingkat monitoring lalu lintas penyelundupan manusia dapat teratasi. Gedung penampungan imigran gelap yang terdapat di markas Polda Lampung terdiri atas dua lantai dan memiliki daya tampung sebanyak 100 orang. ${ }^{12}$ Saat bulan Oktober 2017 diwawancarai peneliti, Polda Lampung menjelaskan bahwa gedung tersebut sudah tidak berfungsi sebagai penampungan imigran gelap seiring tidak berjalannya lagi Satgasda People Smuggling. Penanganan people smuggling di Lampung stagnan sejak tahun 2014, yang sebelumnya gencar tahun 2009-2013.

\section{b. Kebijakan Internasional}

\section{Perjanjian Internasional Mengenai Pencari Suaka yang Melibatkan Indonesia}

\section{Bali Process}

Permasalahan irregular migration diantaranya people smuggling, trafficking in person, pengungsi, pencari suaka serta imigran ilegal di kawasan Asia-Pasifik, telah mendorong negara-negara di kawasan untuk membentuk sebuah mekanisme intraregional guna mengatasi permasalahan yang bersifat lintas negara tersebut. Menyikapi fenomena tersebut, Indonesia dan Australia menggagas penyelenggaraan Bali Regional Ministerial Meeting on People Smuggling, Trafficking in Person and Related Transnational Crime (BRMC I dan BRMC II), masing-masing pada tahun 2002 dan 2003. ${ }^{13}$ Kedua pertemuan tersebut menghasilkan sebuah Regional Consultative

\footnotetext{
${ }^{12}$ Penyelundupan Imigran Gelap, Lampung Tertinggi di Sumatera. http://www.bandarlampungnews.com $/ \mathrm{m} /$ index.php $\quad$ ctn=1\&k=hukum\&i=12166. 10 Juli 2012. Akses pada 10 Oktober 2017).

13 Satu Dekade: Bali Process Gagas Langkah Maju, 13 November 2012, http://theglobal-review.com /lama/content_detail.php?lang=id\&id=10149\&type $=1$ 5\#.XRTmYFZS9dg. Akses pada 17 Oktober 2017.
}

Process (RCP) yang dikenal sebagai Bali Process on People Smuggling, Trafficking in Persons and Related Transnational Crime (Bali Process) dengan Indonesia dan Australia bertindak sebagai Co-chairs. ${ }^{14}$ Sebagai suatu RCP, Bali Process memiliki kekhususan dibandingkan RCP lainnya yaitu sebagai forum dialog dan kerja sama yang mempertemukan negara asal, transit dan tujuan irregular migration. Saat ini keanggotaan Bali Process terdiri atas 45 negara anggota dan 3 organisasi internasional yaitu IOM, UNHCR dan UNODC.

\section{Jakarta Declaration}

Berangkat dari semangat dalam Bali Process, Indonesia menginisiasi Konferensi Regional tingkat Menteri "Special Conference on Irregular Movement of Persons" atau dikenal dengan Jakarta Declaration pada tanggal 20 Agustus 2013 di Jakarta. Sebanyak 12 negara berkumpul di Kementerian Luar Negeri Republik Indonesia untuk membicarakan mengenai isu penyelundupan dan perdagangan manusia dimana pencari suaka adalah salah satu korbannya. $^{15}$

\section{Lombok Treaty}

Lombok Treaty adalah dokumen kesepakatan antara Republik Indonesia dan Australia tentang kerjasama keamanan yang ditandatangani oleh Menteri Luar Negeri Indonesia dan Australia di Lombok pada Tanggal 3 November 2006. Traktat ini mengatur kerjasama dalam sepuluh bidang, yaitu: kerjasama bidang pertahanan, penegakan hukum, anti-terorisme, kerjasama intelijen, keamanan maritim, keselamatan dan keamanan penerbangan, pencegahan

\footnotetext{
${ }^{14}$ Ibid.

${ }^{15}$ Deklarasi Jakarta Kerjasama Multilateral Terhadap Penanggulangan Pencari Suaka dan Manusia Perahu, www.vivanews.com, 24-5-2017. Diakses pada 4 Maret 2017.
} 


\section{Manusia di Wilayah Pesisir \\ Provinsi Lampung}

perluasan (non-proliferasi) senjata pemusnah massal, kerjasama tanggap darurat, organisasi multilateral dan peningkatan saling pengertian dan saling kontak antar masyarakat dan antar perseorangan. ${ }^{16}$

Pasal 3 ayat 7 poin a dalam traktat tersebut menyebutkan bahwa dalam penegakan hukum, salah satu kerjasama yang dijalin adalah dalam bidang penyelundupan dan perdagangan manusia, yang mengacu pada imigran ilegal serta pencari suaka (Agreement Between the Republic of Indonesia and Australia on the Framework for Security Cooperation. Pasal 3 ayat 7 dan ayat 9). Sebagai tindak lanjut dari Lombok Treaty, Australia seringkali memberikan bantuan dana kepada pihak Indonesia untuk mendukung fungsi Indonesia sebagai "benteng pencegah" bagi masuknya imigran ilegal ke Australia. Kerja sama ini lebih kepada pemberantasan pelintas batas negara yang tidak memiliki ijin dan berpeluang dalam terjadinya kejahatan lintas negara dan agenda yang paling penting adalah membuka kerja sama antar institusi kepolisian kedua negara yaitu AFP dan POLRI dalam memberantas kejahatan lintas batas negara seperti terorisme, penyelundupan, human traficking, dan narkoba.

\section{c. Kerjasama Internasional Penanganan People Smuggling}

\section{UNHCR}

UNHCR (United Nations High Commissioner for Refugess) dibentuk oleh Majelis Umum PBB pada tahun 1949 untuk menjalankan 1951 Convention Relating to the Status of Refugees (Konvensi Pengungsi) serta 1967 Protocol Relating to the Status of Refugees (Protokol Pengungsi). Mandat UNHCR adalah menyediakan perlindungan internasional kepada pengungsi yang jatuh di

\footnotetext{
${ }^{16}$ Lombok Treaty Merupakan Kerangka Kerja Sama RI - Australia http://www.dmcindonesia.web.id. Diakses pada 4 Maret 2017.
}

dalam cakupan Konvensi dan Protokol Pengungsi, serta mencari solusi tetap pada masalah pengungsi dengan membantu pemerintah dan organisasi-organisasi yang lain untuk memudahkan repatriasi sukarela pengungsi tersebut atau asimilasinya di dalam masyarakat baru.

Pencari suaka merupakan orang yang mencari perlindungan di negara lain tapi status pengungsinya belum ditentukan bahkan mereka sudah terdaftar atau belum di UNHCR. Biasanya, terpaksa meninggalkan negara asalnya secara cepat dan sebelum dapat mengumpulkan semua surat-surat resminya dan karena itu belum menyelesaikan proses Penentuan Status Pengungsi (PSP). Akibatnya, mereka mengalami situasi yang rentan sekali, baik di negara asalnya, di perjalanan serta jika sudah sampai negara tujuannya karena belum diberikan perlindungan lengkap oleh UNHCR. Pada akhir proses PSP, jika para pencari suaka menenuhi semua kriteriakriteria UNHCR maka mereka disebut pengungsi. ${ }^{17}$

Untuk bisa disebut pengungsi, pencari suaka harus menenuhi kriteriakriteria dari UNHCR. Jadi kriteria utama merupakan:

1) Mereka berada di luar negara asalnya atau mantan negara yang biasa ditinggali;

2) mereka akan menghadapi penganiayaan jika mereka pulang. Penganiayaan tersebut harus atas alasan ras, agama, kewarganegaraan atau keanggotaan pada kelompok atau pendapat politik tertentu dan harus nyata;

3) mereka tidak dapat atau tidak ingin dilindungi oleh negaranya.

\footnotetext{
Houston, Angus, Paris Aristotle, Michael L'Estrange, Report of the Expert Panel on Asylum Seekers, Canberra: Commonwealth of Australia, 2012: 157.
} 


\section{Manusia di Wilayah Pesisir \\ Provinsi Lampung}

Namun, jika di dalam mandat United Nations Relief and Works Agency for Palestinian Refugees in the Near East, sudah melakukan kejahatan serius atau negara penerimanya percaya secara layak mereka akan menjadi ancaman keamanan nasional, mereka tidak akan menerima bantuan UNHCR. $^{18}$

\section{IOM}

IOM memulai operasinya di Indonesia dengan memproses migran Vietnam di Tanjung Pinang, Riau pada 1979 dilanjutkan penanganan para pengungsi Timor Timur. Hubungan IOM dengan pemerintah Indonesia dimulai pada 1999 ketika Indonesia resmi menjadi pengamat dalam dewan IOM. Proyek Penanganan dan Perawatan Imigran Non Reguler (Management and Care of Irregular Immigrants Project - MCIIP) diluncurkan pada 2007 dan selesai pada pertengahan 2009. MCIIP berupaya untuk meningkatkan kapasitas Direktorat Jenderal Imigrasi untuk merawat dan menangani imigran non-reguler di Indonesia melalui pengembangan prosedur operasional standar yang memasukkan instrumen-instrumen HAM; peningkatan fungsi pemulangan Imigrasi Indonesia; serta renovasi dan pelengkapan fasilitas detensi.

\section{d. Kebijakan Negara Tujuan (Australia, Eropa Barat, dan AS)}

\section{Uni Eropa}

Uni Eropa memiliki kompleksitas rezim yang melibatkan rezim freedom of movement, rezim internasional mengenai perlindungan pengungsi, rezim hak asasi manusia, dan rezim keamanan Eropa..

18 Taylor, Savitri dan Brynna Rafferty-Brown, Difficult Journeys: Accessing Refugee Protection in Indonesia, Monash University Law Review 36:3, 2010: 142.
Absennya solidaritas bersama antar negaranegara Uni Eropa dalam menghadapi isu pengungsi dan pencari suaka menjadi dorongan bagi Jerman untuk menjalankan strategic inconsistency. ${ }^{19}$

Jerman menggunakan kekuatan politik-ekonomi tersebut, Jerman menjadi perantara bagi Uni Eropa dan Turki dalam skema perjanjian dalam menangani gelombang pengungsi dan pencari suaka. Jerman sepakat untuk memindahkan pengungsi dan pencari suaka yang mendarat di Italia dan Yunani ke Turki. Di sini terlihat inkonsistensi Jerman terhadap rezim hak asasi manusia. Jerman juga memaksimalkan individual situation-nya untuk meminta bantuan pasukan koalisi NATO agar ikut mengawasi proses pemindahan pengungsi dan pencari suaka yang dikirim dari Italia dan Yunani ke Turki melalui jalur laut. Kebijakan ini dikategorikan sebagai bentuk militerisasi dan tindakan represif terhadap pengungsi dan pencari suaka, yang bertentangan dengan hak asasi. Selain itu, Jerman melakukan tindakan yang bertentangan dengan rezim freedom of movement melalui pemberlakukan cek dan kontrol di wilayah perbatasan dengan Austria dan Italia. ${ }^{20}$

\section{Amerika Serikat}

Presiden Amerika Serikat Donald Trump menangguhkan program pengungsi AS selama 120 hari. Ia juga melarang imigran dari tujuh negara muslim masuk ke AS, yaitu Suriah, Irak, Iran, Libya, Somalia, Sudan, dan Yaman. Ia memerintahkan peningkatan pemeriksaan untuk setiap imigran agar menjaga masuknya kelompok teroris dan radikal di Amerika Serikat.

\footnotetext{
19 Adelina Pertiwi, Lunyka, Kompleksitas Rezim di Uni Eropa: Upaya Penanganan Pengungsi dan Pencari Suaka, Jurnal Ilmu Sosial dan Ilmu Politik, Volume 19, Nomor 3, Maret 2016: 218-233.

${ }^{20}$ Ibid.
} 


\section{Manusia di Wilayah Pesisir \\ Provinsi Lampung}

\section{Australia}

Pada tanggal 18 November 2014, Menteri Imigrasi Australia, Scott Morrison, mengumumkan pemerintah Australia tidak akan menerima pengungsi lagi dari kantor UNHCR di Jakarta yang mendaftar setelah tanggal 1 Juli 2014. Dari Indonesia, Australia hanya menerima pengungsi yang sudah bersertifikasi. Para pencari suaka dan pengungsi yang tercatat di UNHCR Jakarta sebelum tanggal tersebut dan sudah atau akan, serta menenuhi kriteria pengungsi UNHCR, masih ada kesempatan diterima Australia dalam Humanitarian Programme. Namun, ada kebijakan asupan pengungsi yang melalui wilayah Indonesia ke Australia setiap tahun 600 orang dikurangi hingga 450 orang pada tahun 2014-2015. Tujuan perubahan ini, menurut Australia adalah mengurangi penyelundupan manusia dari wilayah Indonesia ke Australia. Berhenti mengambil pengungsi dari UNHCR Indonesia tidak akan menghentikan semua pencari suaka yang datang dari Timur Tengah dan negara-negara di Asia Tenggara menuju kawasan Australia. ${ }^{21}$

\section{Diskusi}

Masalah people smuggling merupakan ancaman yang tinggi bagi Indonesia. Hal itu dinilai dari aspek kerentanan negara (vulnerabilities), tujuan masuknya orang asing (intention) dan kapabilitas negara (capabilities). Peningkatan jumlah temuan kasus, dengan varian tujuan migrasi non reguler ke Indonesia, belum direspon oleh Pemerintah dengan regulasi memadai dan upaya penanganan.

\footnotetext{
${ }^{21}$ Snailham, Kate, Australia Tutup Pintu Pengungsi Kebijakan Suaka Australia yang Baru di Indonesia. Australian Consortium for In-Country Indonesian Studies (ACICIS) Fakultas Ilmu Sosial dan Ilmu Politik, Universitas Katolik Parahyangan, Bandung Desember 2014.
}

Pada aspek regulasi, kelemahan Indonesia belum menandatangani Konvensi Jenewa Tahun 1951 dan Protokol Tahun 1967, posisinya sangat lemah dalam mengatasi masalah para pencari suaka dan pengungsi dari negara lain karena tidak memiliki peraturan nasional yang secara khusus membahas masalah tersebut. Selain itu, keberadaan UNHCR di Jakarta membuat Pemerintah Republik Indonesia merujuk setiap orang asing yang masuk dengan alasan mencari suaka ke UNHCR untuk melaksanakan penentuan status pengungsi. Pemerintah Indonesia mengizinkan para imigran untuk menetap di Indonesia hingga didapatkan suatu solusi. Indonesia menyerahkan kewenangan penentuan status pencari suaka pada UNHCR, dengan dibantu oleh IOM yang selama ini memberikan bantuan materi untuk kebutuhan pangan dan medis para pencari suaka yang tinggal di rudenim.

Pada aspek penanganan, secara internal telah ada tim penanganan dari pemerintah pusat yang dikoordinasikan melalui jaringan lembaga. Badan Koordinasi Utama adalah Kementerian Koordinasi Politik, Hukum, dan Keamanan. Melalui Desk Penyelundupan Manusia, badan nasional antardepartemen untuk Pengungsi, Pencari Suaka, dan Penyelundupan Manusia terjalin kerjasama dengan Kepolisian RI, Kementerian Luar Negeri, Imigrasi, Kejaksaan RI, TNI, pemerintah daerah, IOM, dan UNHCR. Namun dalam pelaksanaannya, beberapa kendala adalah Indonesia yang secara geografis merupakan negara kepulauan, kekurangan satuan tugas dan sistem pengamanan wilayah serta aparatur perbatasan yang minim pemahaman tentang people smuggling. Beban pemerintah Indonesia ketika migrasi non reguler meningkat sementara penantian status pengungsi membutuhkan waktu lama, dan pengungsi yang tidak tertampung di rudenim dengan fasilitas terbatas. Selanjutnya anggaran yang terbatas untuk penanganan khusus people smuggling. Bentuk kegiatan 


\section{Provinsi Lampung}

dan anggaran juga masih tergantung kepada jalinan kerjasama dengan IOM, UNHCR, dan negara-negara maju tujuan para migran. Penanganan juga dipengaruhi faktor eksternal, yaitu keterbatasan IOM dan UNHCR sebagai organisasi internasional yang menangani pengungsi, dan perubahan kebijakan negara tujuan yang cenderung mengurangi penerimaan terhadap pengungsi. Perubahan kebijakan Australia yang menutup pintu bagi pengungsi sejak tahun 2014, diikuti perubahan kebijakan yang ketat dalam penerimaan pengungsi oleh Uni Eropa dan Amerika Serikat.

Penanganan people smuggling di Lampung, gencar sekitar tahun 2008 dan meredup sekitar tahun 2015. Ada ketergantungan pemda terhadap anggaran dan program pemerintah pusat, termasuk terhadap jaringan kerjasama yang terbangun oleh pemerintah pusat dengan organisasi internasional dan negara tujuan para pengungsi.

Indonesia juga melibatkan diri dalam perjanjian internasional mengenai pencari suaka sebagai forum dialog dan kerja sama yang mempertemukan negara asal, transit dan tujuan irregular migration, pembahasan isu penyelundupan dan perdagangan manusia dimana pencari suaka adalah salah satu korbannya. Selanjutnya kesepakatan antara Republik Indonesia dan Australia tentang kerjasama keamanan.

\section{Kesimpulan dan Rekomendasi}

Penanganan kejahatan penyelundupan manusia yang masuk dan keluar melintasi wilayah provinsi termasuk Provinsi Lampung adalah tetap tergantung kepada kebijakan pemerintah pusat. Indonesia yang belum meratifikasi Konvensi Internasional 1951 dan Protokol 1967 tentang status pengungsi. Hal penting meratifikasi adalah pemerintah bisa langsung menetapkan sebagai pencari suaka atau pengungsi sesuai dengan kepentingan nasional Indonesia dan pertimbangan faktor keamanan negara. Selain itu juga mendapat bantuan kerjasama internasional terkait penguatan kapasitas nasional dalam penanganan pengungsi dan pencari suaka. Apabila ratifikasi konvensi terabaikan maka menjadi peluang ancaman bagi keamanan pemerintah daerah. Akibat dari kedatangan para ilegal migran, diantaranya adalah pengaruh ilegal migran terhadap persebaran ideologi radikalisme, kejahatan narkoba, human traficking, dansebagainya. Pemerintah daerah seperti

Provinsi Lampung tidak menyediakan khusus anggaran mengenai penjagaan keamanan wilayahnya terkait penyelundupan manusia. Selama belum ada peraturan hukum nasional mengenai kejahatan penyelundupan manusia, Pemerintah menggunakan UU Keimigrasian, yang dalam implementasinya menimbulkan persoalan peningkatan beban pemerintah dengan rumah detensi migrannya dan implementasi HAM untuk para pengungsi. Peneliti, karena mempertimbangkan masih lemahnya aspek hukum dan pelaksanaan penanganan penyelundupan manusia, merekomendasikan kepada pemerintah daerah Provinsi Lampung untuk memberikan pemahaman kepada ada. 
Dwi Wahyu H, I Gede Sidemen, Yuni Ratnasari | Penanganan Penyelundupan

Manusia di Wilayah Pesisir

Provinsi Lampung

\section{DAFTAR PUSTAKA}

Buzan, Barry, Security: A New Framework for Analysis, Boulder: Lynne Rienner Publishers, 1998.

Buzan, Barry, Marianne Stone, Security According to Buzan: A Comprehensive Security Analysis, New York: Columbia University, 2009.

Houston, Angus, Paris Aristotle, Michael L'Estrange, Report of the Expert Panel on Asylum Seekers, Canberra: Commonwealth of Australia, 2012.

Imigrasi Lampung Amankan Ratusan Imigran dalam 3 tahun. Diakses dari http://www.cendananews.com /2015/04/ imigrasi-lampung-amankan-ratus-an.html. 18 April 2015, pada 17 Oktober 2017.

Lombok Treaty Merupakan Kerangka Kerja Sama RI - Australia http://www.dmcindonesia.web.id , 4 Maret 2017.

Imigrasi Nasional dan Problem Pencari Suaka, Badan Penanganan Sumber Daya Manusia dan HAM Kementerian Hukum dan Hak Asasi Manusia Republik Indonesia, http://bpsdm.kemenkumham.go.id/artikel-bpsdm/130-imigrasi-nasional-dan-problempencarisuaka, 5 Agustus 2017.

, MoU Komnas HAM dan UNHCR Dorong Perlindungan Pengungsi dan Pencari Suaka, https://www.komnasham. go.id/index.php/ news/2015/07/28/173/mou-komnas-hamdan-unhcr-dorong-perlindungan-pengungsi-dan-pencari-suaka.html. Selasa, 28 Juli 2015.

29 April 2017.

. Deklarasi Jakarta Kerjasama Multilateral Terhadap Penanggulangan Pencari Suaka dan Manusia Perahu, www.vivanews.com, 24-5-2017.

- Penyelundupan Imigran Gelap, Lampung Tertinggi di Sumatera. http://www.bandarlampungnews.com/m/index.php $\quad$ ?ctn=1\&k=hukum\&i=12166, 10 Juli 2012.

Satu Dekade: Bali Process Gagas Langkah Maju, 13 November 2012, http://theglobalreview.com/lama/content_detail.php?lang=id\&id=10149\&type=15\#.XRTmYFZS9dg. Akses pada 17 Oktober 2017.

Gallagher, Anne and Marie McAuliffe, South-East Asia and Australia dalam Migrant Smuggling Data and Research: A Global Review of The Emerging Evidence Base, International Organization for Migration, 2016.

Hanson, Gordon H., The Economic Logic of Illegal Migration, Council Special Reports (CSR) No.26, April, USA: Council on Foreign Relations, 2007. 
Dwi Wahyu H, I Gede Sidemen, Yuni Ratnasari | Penanganan Penyelundupan

Manusia di Wilayah Pesisir

Provinsi Lampung

Taylor, Savitri dan Brynna Rafferty-Brown, Difficult Journeys: Accessing Refugee Protection in Indonesia, Monash University Law Review 36:3, 2010.

2014. Upaya Memerangi Penyelundupan Manusia Pada Tahun 2013. 2014. Report IOM Indonesia Januari 2014.

IOM Indonesia Irregular Migrant People Smuggling Public Information Campaign

(PIC). Market Research Report Klirkom. Released Under The FOI Act 1982.

Snailham, Kate, Australia Tutup Pintu Pengungsi Kebijakan Suaka Australia yang Baru di Indonesia. Australian Consortium for In-Country Indonesian Studies (ACICIS) Fakultas Ilmu Sosial dan Ilmu Politik, Universitas Katolik Parahyangan, Bandung Desember 2014.

Zikri, Manshur, Permasalahan Imigran Gelap Dan People Smuggling Dan Usaha-Usaha Serta Rekomendasi Kebijakan dalam Menanggulanginya. Tugas Akhir Mata Kuliah Kebijakan Kriminal, Fakultas Ilmu Sosial Dan Ilmu Politik, Universitas Indoesia, 2010.

Netanyahu, Kurniawan. 2018. Upaya Penanganan People Smuggling Oleh Sekretariat NCBINTERPOL Indonesia Dan Australian Federal Police Tahun 2015 - 2017, Skripsi, Program Studi Hubungan Internasional Fakultas Ilmu Sosial dan Ilmu Komunikasi, Universitas Satyawacana.

Adelina Pertiwi, Lunyka, Kompleksitas Rezim di Uni Eropa: Upaya Penanganan Pengungsi dan Pencari Suaka, Jurnal Ilmu Sosial dan Ilmu Politik, Volume 19, Nomor 3, Maret 2016.

Heckmann, Friedrich, Illegal Migration: What Can We Know and What Can We Explain? The Caase of Germany. International Migration Review, Vol.38 No.3, 2004, hlm. 11031125 .

Kass, Lani, Homeland Defense: Assumption First, Strategy Second, Journal of Homeland Security. Vol. 1, 2004.

Kristin, Debby dan Chloryne Trie Isana Dewi, Tindak Pidana Kejahatan Penyelundupan Manusia (People Smuggling) di Indonesia: Tanggung Jawab Indonesia dan Australia. Padjadjaran Journal of International Law, Volume 1, Number 1, Januari 2017.

Martin, Philip \& Mark Miller, Smuggling and Trafficking: A Migration Review, Vol.34, No.3, Autumn, 2000, hlm 969.

Septia Anggrainy, Vindy, Perlindungan Pengungsi Lintas Batas Negara di Indonesia Menurut Hukum Internasional, Lex et Societatis, Vol. II, No. 1, Januari 2014.

Zulya, Rizkan, Geetha Subramaniam, Tan Kamello. 2014. People Smuggling In Indonesia. International Journal of Asian Social Science. ISSN(e): 2224-4441/ISSN(p): 2226-5139. AESS Publications, Journal homepage: http://www.aessweb.com/journals/5007, 2014. 